\title{
Voltammetric Studies on the Role of Additives in Bright Zinc Electrodeposition from an Alkaline Non-Cyanide Bath
}

\author{
S. Shanmugasigamani, ${ }^{l}$ M. Pushpavanam ${ }^{2, *}$ \\ ${ }^{l}$ Central Electrochemical Research Institute, Karaikudi 630 006, TN, India \\ ${ }^{2}$ A.C. College of Engineering \& Technology, Karaikudi-630 004, TN, India
}

Received 3 July 2009; accepted 26 October 2009

\begin{abstract}
Influence of various carrier additives and brightener additives on the voltammetric behavior of zinc electro deposition from an alkaline non-cyanide bath was studied. Two different cathodic peaks were observed. Peak I has been attributed to hydrogen reduction / UPD of zinc and peak II to reduction of the metal. The extent of polarization of the zinc deposition to more negative potentials and the corresponding peak current decide the nature of deposits. PVA was found to be the best carrier additive. PVA chains retain zinc hydroxyl anions and control the speed of the rate determining step. Unsaturated aldehydes bring about 3-dimensional nucleation and further increase the polarization when added with PVA.
\end{abstract}

Keywords: addition agents, alkaline non-cyanide bath, bright zinc plating, cyclic voltammetry, potential scan range.

\section{Introduction}

Alkaline non-cyanide zinc baths are the outcome of the efforts to produce a nontoxic cyanide free zinc electrolyte. Formerly, it was thought that these baths can produce only dark, spongy or powdery deposits and addition of complexing agents like EDTA, gluconate, tartrate and triethanolamine [1] in relatively large quantities can improve the deposit quality.

However, this created effluent treatment problems. The modern alkaline noncyanide baths make use of organic addition agents in negligible quantities to produce commercially acceptable bright deposits.

A number of organic additives are reported in the literature, which fall into two categories - the carrier additive and the brightener. Generally, the carrier additive would enable grain refinement and the brightener additive would have a complementary effect in producing bright deposits. Since most of the

\footnotetext{
* Corresponding author. E-mail address: malathypush@yahoo.com
} 
formulations are proprietary in nature, a detailed study to explore a viable combination of the additives becomes essential [2-5].

Our earlier communication [3] dealt with the development of a suitable brightener formulation for an alkaline non-cyanide zinc bath. A number of organic compounds have been tested as carrier and brightening additives and the best composition is reported [3]. In this paper, the effect of these additives on the voltammetric behavior of zinc deposition from an alkaline non-cyanide bath is reported.

\section{Experimental techniques}

An alkaline non-cyanide zinc bath, given in Table 1, was prepared using analytical grade reagents. The bath was prepared as a stock solution, purified by zinc dust treatment, filtered and used for the experiments. Rochelle salt (RS), nicotinic acid (NA), triethanolamine (TEA), tetra-ethylene pentammine (TEPA), polyvinyl alcohol (PVA), and vanillin (VA), were used as the carrier additives, and piperonal (PA), veratraldehyde (VER), anisaldehyde (ANI), vanillin (VA), and benzimidazole (BZ) were used as the brightener additives in association with the best carrier additive identified. Analytical grade additives were prepared as stock solutions either in water or in ethanol and added to the electrolyte in required amounts.

Table 1. Bath composition used.

\begin{tabular}{|c|c|}
\hline Constituents & Concentration, g/L \\
\hline Zinc Oxide & $9-12$ \\
& $90-120$ \\
\hline
\end{tabular}

A conventional $\mathrm{H}$ type three necked cell was used for the cyclic voltammetric study. A polished mild steel cathode of $0.28 \mathrm{~cm}^{2}$, embedded in a Teflon sleeve was used as the working electrode (WE) with a platinum counter electrode (CE). A calomel electrode was used as the reference.

The cell was connected to a potentiostat (Wenking, Germany), a scan generator (Wenking, Germany), and an X-Yt recorder (Rikadenki, Germany). Potentials were scanned between $-1200 \mathrm{mV}$ to $-1700 \mathrm{mV}$ at a scan rate of $10 \mathrm{mV} \mathrm{sec}{ }^{-1}$.

From the voltammograms, the peak potentials and peak currents corresponding to the reduction of zinc ions were identified. Since the paper deals only with the cathodic reduction of zinc ions, the cathodic sweep of the voltammogram alone is represented in Figs. 1-6 and the remaining figures show the full voltammogram in order to show the cross over exhibited by them in the reverse sweep. 


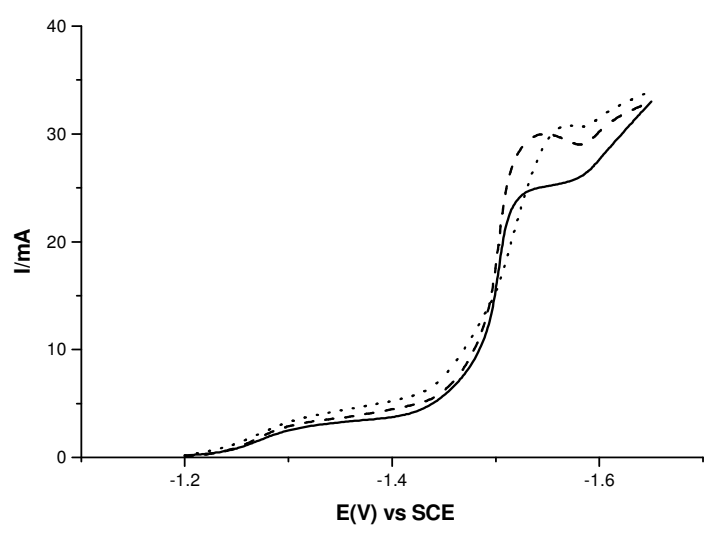

Figure 1. Effect of addition of RS as carrier additive on the voltammetric behavior of zinc deposition from basic electrolyte. Scan range $-1200 \mathrm{mV}$ to $-1700 \mathrm{mV}$; scan rate of $10 \mathrm{mV} \mathrm{sec}{ }^{-1}$. Plain zinc (-); Plain zinc + RS $5 \mathrm{~g} / \mathrm{L} \mathrm{(-—);} 10 \mathrm{~g} / \mathrm{L} \mathrm{(-} \mathrm{-} \mathrm{).}$

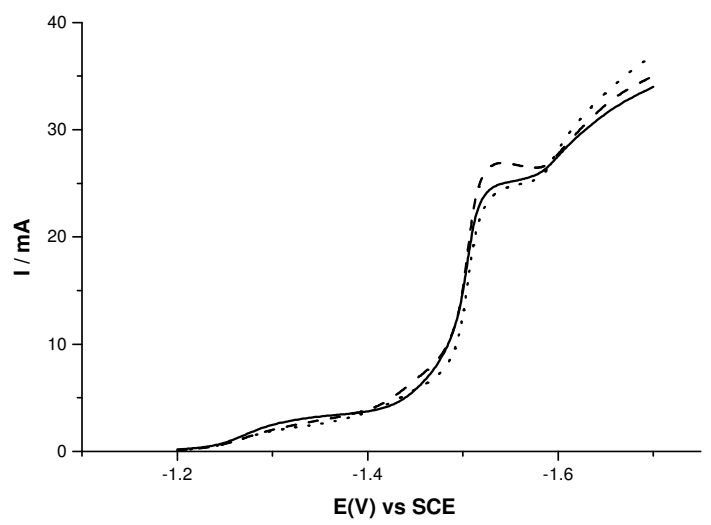

Figure 2. Effect of addition of NA as carrier additive on the voltammetric behavior of zinc deposition from basic electrolyte. Conditions as in Fig. 1. Plain zinc (-); plain zinc + NA $5 \mathrm{~g} / \mathrm{L}$ (- - $) ; 10 \mathrm{~g} / \mathrm{L}(--$-).

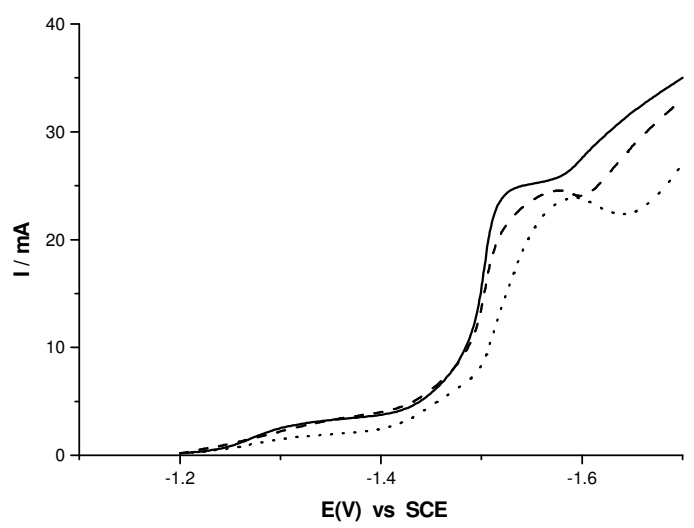

Figure 3. Effect of addition TEA as carrier additive on the voltammetric behavior of zinc deposition from basic electrolyte. Conditions as in Fig. 1. Plain zinc (-); plain zinc + TEA $5 \mathrm{~mL} / \mathrm{L}(--) ; 10 \mathrm{~mL} / \mathrm{L}(---)$. 


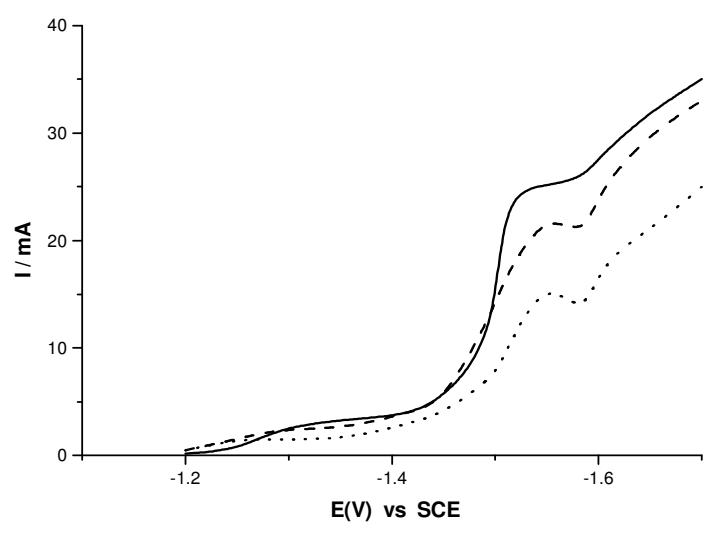

Figure 4. Effect of addition of TEPA as carrier additive on the voltammetric behavior of zinc deposition from basic electrolyte. Conditions as in Fig. 1. Plain zinc (-); plain zinc + TEPA $5 \mathrm{~mL} / \mathrm{L}(--) ; 10 \mathrm{~mL} / \mathrm{L}(---)$.

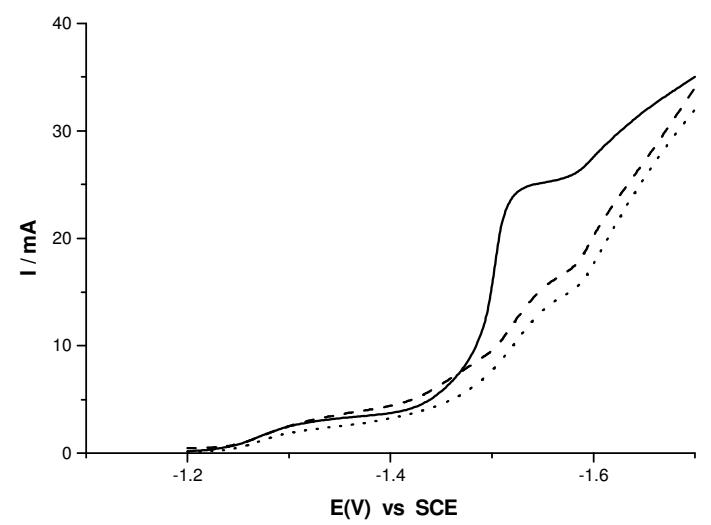

Figure 5. Effect of addition of PVA as carrier additive on the voltammetric behavior of zinc deposition from basic electrolyte. Conditions as in Fig. 1. Plain zinc (-); plain zinc + PVA $1.5 \mathrm{~g} / \mathrm{L}(--) ; 2.0 \mathrm{~g} / \mathrm{L}(--$-).

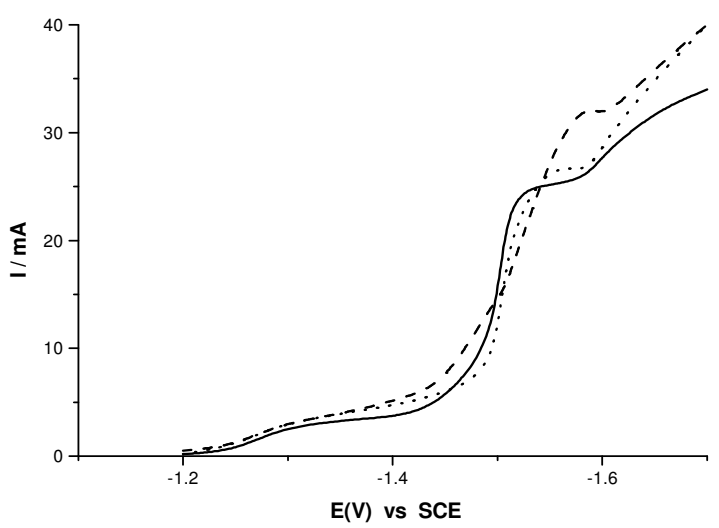

Figure 6. Effect of addition of VA as carrier additive on the voltammetric behavior of zinc deposition from basic electrolyte. Conditions as in Fig. 1. Plain zinc (-); plain zinc + VA $0.5 \mathrm{~g} / \mathrm{L}(--) ; 1.0 \mathrm{~g} / \mathrm{L}(---)$. 


\section{Results and discussion}

The cathodic sweep of the voltammograms generally exhibited two cathodic peaks, one at around $-1.30 \mathrm{~V}$ and the other in the potential range of -1.55 to $1.60 \mathrm{~V}$ versus SCE. The formation of two peaks in presence of additives has already been reported [6]. The former could be associated with incipient hydrogen reduction followed by zinc UPD.

$$
\begin{array}{llll}
2 \mathrm{H}_{2} \mathrm{O}+2 \mathrm{e}^{-} & \leftrightarrows \mathrm{H}_{2}+2 \mathrm{OH}^{-} & \mathrm{E}_{\mathrm{o}}=-0.828 \mathrm{~V} \\
\mathrm{Zn}^{2+}+\mathrm{OH}^{-}+\mathrm{e}^{-} & \rightarrow \mathrm{Zn}(\mathrm{OH})_{\text {ads }} & \mathrm{E}_{\mathrm{o}}=-0.89 \mathrm{~V}
\end{array}
$$

Previous studies report that the inhibition of HER (Hydrogen Evolution Reaction) in the presence of zinc ions in alkaline [7-10] and acid [11] baths is due to the formation of a sub-monolayer of $\mathrm{Zn}$ on ferrous substrates. It is proposed that zinc UPD competes with proton reduction [12-13].

The second is clearly associated with the reduction of $\mathrm{Zn}^{++}$to $\mathrm{Zn}^{\circ}$ corresponding to the reaction

$$
\mathrm{Zn}(\mathrm{OH})_{4}{ }^{2-}+2 \mathrm{e}-\quad \leftrightarrows \quad \mathrm{Zn}+4 \mathrm{OH}^{-} \quad \mathrm{E}_{\mathrm{o}}=-1.214 \mathrm{~V}
$$

This peak is followed by increase in current due to hydrogen evolution reaction (HER).

Figs. 1 - 6 show the effect of adding different carrier additives viz. RS, NA, TEA, TEPA, PVA and VA at different concentrations on the voltammetric behavior of zinc deposition. The cathodic sweeps generally show three different regions corresponding to a) hydrogen reduction plateau, at $\mathrm{E}_{\mathrm{cp} 1}$, b) zinc reduction at $\mathrm{E}_{\mathrm{cp} 2}$ with a distinct peak or a plateau merged with the subsequent HER peak and c) HER reaction. When the sweep was reversed, (shown only in Figs.7-11) an oxidation peak was observed at $-1.5 \mathrm{~V}$ corresponding to the dissolution of the deposited zinc.

$\mathrm{E}_{\mathrm{cp} 1}$ occurs at around $-1.3 \mathrm{~V}$ and in certain cases at higher additive concentrations slight suppression in $I_{c p 1}$ values was observed. This might be due to the adsorption of additives on the electrode surface suppressing the hydrogen reduction reaction. Zinc deposition $\left(\mathrm{E}_{\mathrm{cp} 2}\right)$ occurs in the potential range of -1.55 to $-1.6 \mathrm{~V}$ depending up on the additive used. The voltammetric data are presented in Table 2.

In presence of RS, NA, TEA and VA (Figs.1-3 and 6), the voltammetric curves do not show appreciable polarization. In the case of $\mathrm{RS}, \mathrm{Na}$ and $\mathrm{VA}$ the $\mathrm{I}_{\mathrm{cp} 2}$ values showed an increase with a marginal change in $\mathrm{E}_{\mathrm{cp} 2}$, whereas with TEA, slight polarization with marginal increase in the peak current value is observed. PVA and TEPA showed shift in the voltammetric curves as well as considerable reduction in $\mathrm{I}_{\mathrm{cp} 2}$ values (Table 2) which is more with PVA than with TEPA. It is clear that PVA forms a stronger complex with zinc ions which can lead to smooth deposition. Hence, PVA was chosen as the carrier additive for the subsequent studies on brightener additives. 


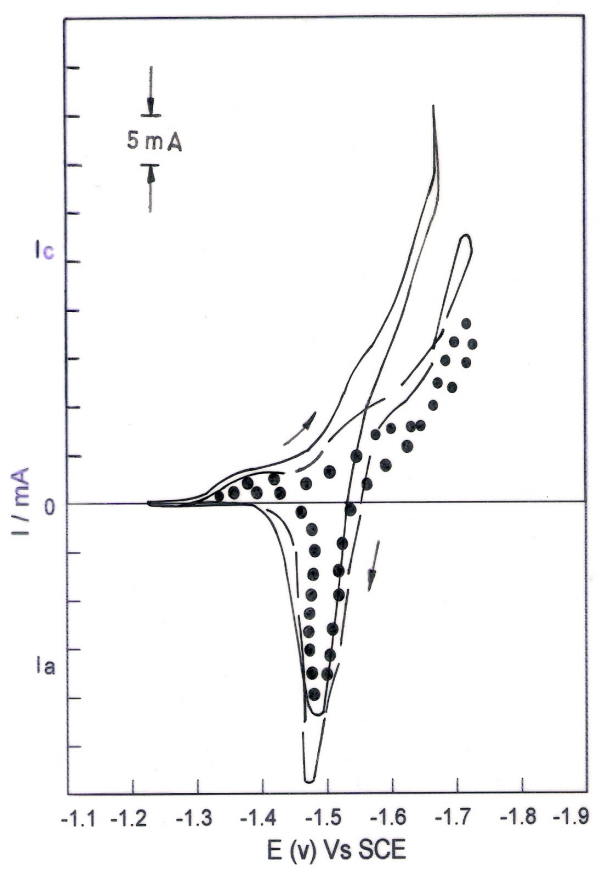

Figure 7. Effect of addition of PIP as brightener additive on the cyclic voltammetric behavior of zinc deposition from basic electrolyte containing PVA (1.5 g/L). Scan range $-1200 \mathrm{mV}$ to $-1700 \mathrm{mV}$; scan rate of $10 \mathrm{mV} \mathrm{sec}{ }^{-1}$. Plain zinc + PVA (-); plain zinc + PVA + PIP $1.0 \mathrm{~g} / \mathrm{L}(--) ; 1.5 \mathrm{~g} / \mathrm{L}(\bullet \bullet \bullet \bullet)$.

Zinc deposition from zincate baths without any additive could yield only mossy dark deposits. The following four step reaction path has been proposed [14] for the deposition of zinc from zincate solution:

$$
\begin{array}{lll}
\mathrm{Zn}(\mathrm{OH})_{4}{ }^{2-} & \leftrightarrows & \mathrm{Zn}(\mathrm{OH})_{3}{ }^{-}+\mathrm{OH}^{-} \\
\mathrm{Zn}(\mathrm{OH})_{3}{ }^{-}+\mathrm{e}^{-} & \rightarrow & \mathrm{Zn}(\mathrm{OH})_{2}^{-}+\mathrm{OH}^{-} \\
\mathrm{Zn}(\mathrm{OH})_{2}^{-} & \leftrightarrows & \mathrm{ZnOH}+\mathrm{OH}^{-} \\
\mathrm{ZnOH}+\mathrm{e}^{-} & \rightarrow & \mathrm{Zn}+\mathrm{OH}^{-}
\end{array}
$$

with reaction ( $\mathrm{v}$ ) as the rate determining step. Since $\mathrm{Zn}^{2+}$ prefers to exist as a tetra or hexa-coordinate species, the coordinated $\mathrm{Zn}(\mathrm{OH})_{3}{ }^{-}$is more likely to exist as $\mathrm{Zn}(\mathrm{OH})_{3}\left(\mathrm{H}_{2} \mathrm{O}\right)^{-}$, thus step (v) becomes

$$
\mathrm{Zn}(\mathrm{OH})_{3}\left(\mathrm{H}_{2} \mathrm{O}\right)^{-}+\mathrm{e}^{-} \rightarrow \quad \mathrm{Zn}(\mathrm{OH})_{2}^{-}+\mathrm{H}_{2} \mathrm{O}+\mathrm{OH}^{-}
$$

Since the rate of reaction (viii) is faster than the rate of transport of electro active species to the site of discharge, powdery non-adherent deposits result. Thus, in order to achieve bright, useful deposits the rate of reaction (viii) must be reduced. This can be achieved with organic additives, which either modify step (v/viii) or bring about selective deposition [14-17]. The additives should (a) form a stable 
complex with zinc to delay the above reaction and (b) be reducible with a moderate polarization to form an acceptable deposit on electrolysis.

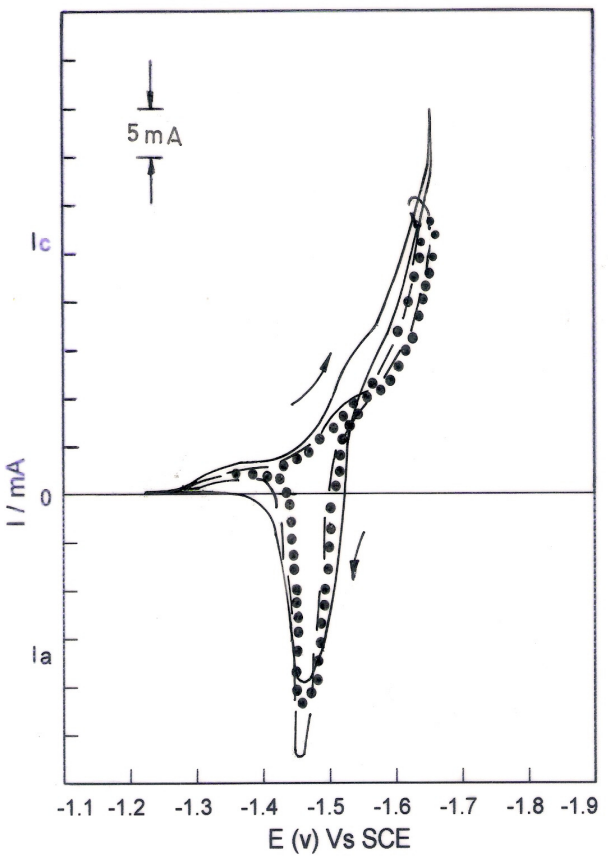

Figure 8. Effect of addition of VER as brightener additive on the cyclic voltammetric behavior of zinc deposition from basic electrolyte containing PVA. Conditions as in Fig. 1. Plain zinc + PVA (-); plain zinc + PVA + VER 0.4 g/L (-—); $0.6 \mathrm{~g} / \mathrm{L}(\bullet \bullet \bullet \bullet)$.

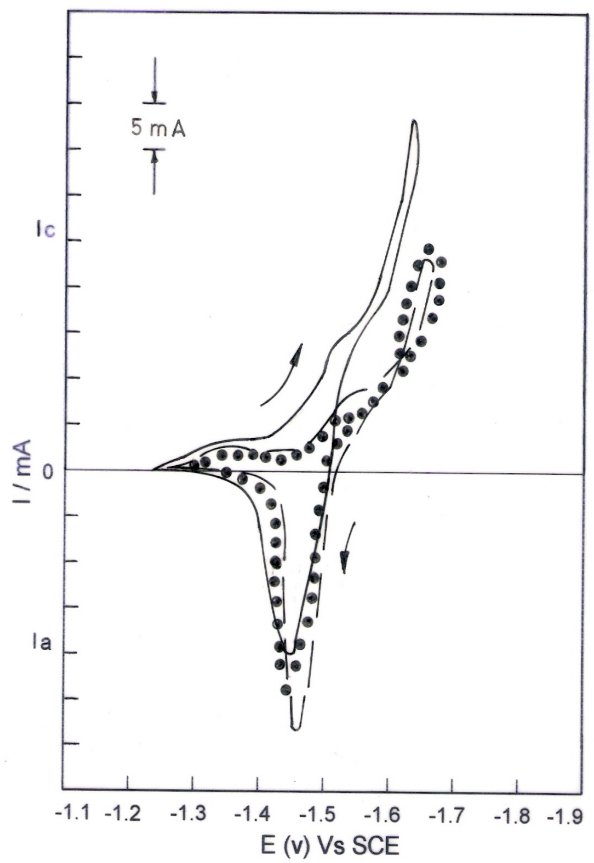

Figure 9. Effect of addition of ANI as brightener additive on the cyclic voltammetric behavior of zinc deposition from basic electrolyte containing PVA. Conditions as in Fig. 1. Plain zinc + PVA (-); plain zinc + PVA + ANI 0.4 g/L (-—); $0.6 \mathrm{~g} / \mathrm{L}$ 
RS, NA, TEA and VA do not contribute anything to delay reaction (viii) as indicated by an increase in $I_{c p 2}$ values. PVA shows lowest $I_{c p 2}$ than TEPA, indicating its better complexing ability. It has been shown in our previous study [3] that TEPA gives only streaky deposits which could be due to its less efficient control of reaction (v/viii).

Owing to the polarity of the carbon-oxygen bond, PVA is present in significant amounts in the cathode film, forming a weak physical barrier that hinders zinc deposition. It is also possible that PVA replaces the $\mathrm{H}_{2} \mathrm{O}$ present in the complex $\mathrm{Zn}(\mathrm{OH})_{3}{ }^{-} \mathrm{H}_{2} \mathrm{O}$, i.e.,

$$
\mathrm{PVA}+\mathrm{Zn}(\mathrm{OH})_{3}{ }^{-}\left(\mathrm{H}_{2} \mathrm{O}\right) \quad \rightarrow \quad \mathrm{PVA}-\mathrm{Zn}(\mathrm{OH})_{3}{ }^{-}
$$

In this way the PVA chains can retain zinc hydroxyl anions and control the speed of the rate determining step which would then become

$$
\mathrm{PVA}-\mathrm{Zn}(\mathrm{OH})_{3}^{-}+\mathrm{e}^{-} \quad \rightarrow \quad \mathrm{PVA}+\mathrm{Zn}(\mathrm{OH})_{2}^{-}+\mathrm{OH}^{-}
$$

Assuming reaction (x) as being much slower than (v) because of the energy needed to break the PVA complex, would explain the grain refining properties of PVA [18].

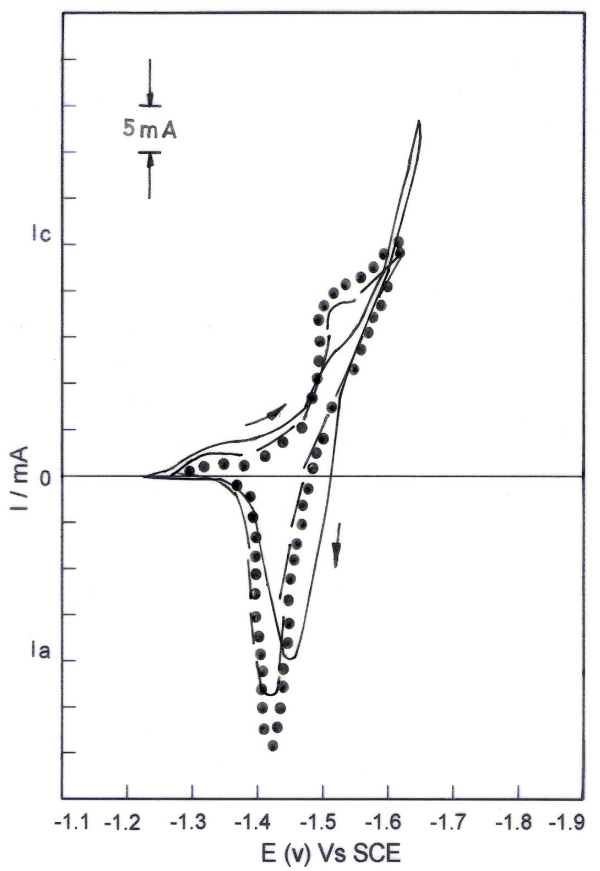

Figure 10. Effect of addition of VA as brightener additive on the cyclic voltammetric behavior of zinc deposition from basic electrolyte containing PVA. Conditions as in Fig. 1. Plain zinc + PVA (-); plain zinc + PVA + VA $1.0 \mathrm{~g} / \mathrm{L}(--) ; 1.5 \mathrm{~g} / \mathrm{L}(\bullet \bullet \bullet \bullet)$.

Figs. 7-11 show the combined effect of brightener additives at different concentrations in presence of the carrier additive (PVA) on the voltammetric behavior. Table 3 shows the $\mathrm{CV}$ data obtained in presence of carrier and brightener additives in alkaline zinc electrolyte. It could be seen that VA and BZ 
show higher $\mathrm{I}_{\mathrm{cp} 2}$ than that observed in presence of PVA alone. The depolarization caused by them offsets the effect of PVA in modifying the nature of deposits. These additives do not show cross over in the reverse scan indicating the absence of three dimensional nucleation which is required for producing coherent, compact deposits unlike the other three brightener additives viz. PIP,VER and ANI.

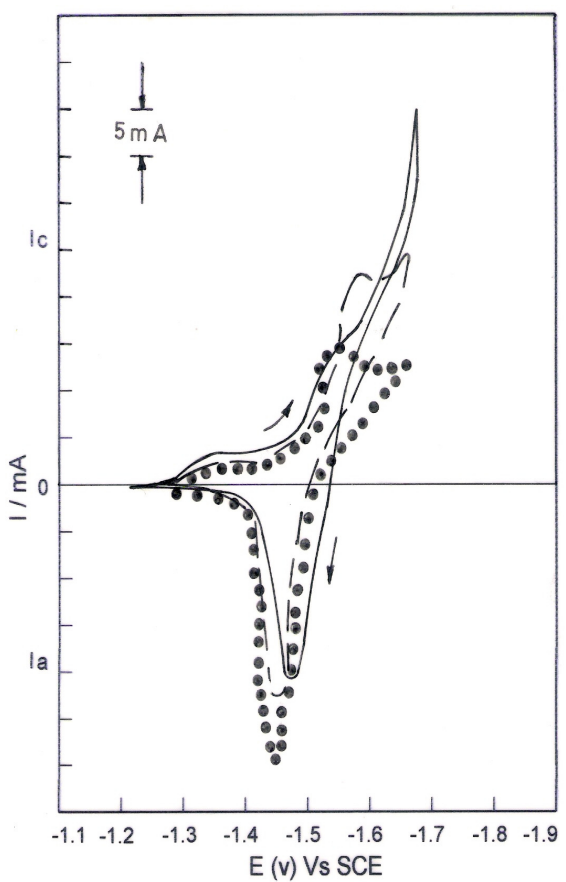

Figure 11. Effect of addition of $\mathrm{BZ}$ as brightener additive on the cyclic voltammetric behavior of zinc deposition from basic electrolyte containing PVA. Conditions as in Fig. 1. Plain zinc + PVA (-); plain zinc + PVA + BZ $10 \mathrm{~g} / \mathrm{L}(--) ; 15 \mathrm{~g} / \mathrm{L}(\bullet \bullet \bullet \bullet)$.

With increase in concentration, PIP increases polarization of the cathodic reduction and significantly reduces the $I_{c p 2}$ and does not appreciably change the $\mathrm{E}_{\mathrm{cp} 2}$. ANI shows a higher polarization than the other two, as indicated by the more negative $E_{c p 2}$ value and least $I_{c p 2}$ compared to the other two. This is in agreement with our earlier report saying that ANI gives least current efficiency of all the three aldehydes [3]. VER showed an intermediate behavior. Since, PIP does not appreciably alter the $\mathrm{E}_{\mathrm{cp} 2}$ value obtained in presence of PVA alone and the $\mathrm{I}_{\mathrm{cp} 2}$ values are also higher than those observed with the other two aldehydes, PIP (1.0 g/L) was selected as the best brightener additive to work with PVA.

The roll of brightener additives is to further refine the structure by specific adsorption on the electrode surface increasing the polarization and reducing the peak currents. An increase in polarization is generally observed in the presence of additives [19 - 27]. These properties and the cross-over observed, make PIP, VER and ANI as good brightening additives. However, ANI and VER show a reduction in peak currents to a higher extent than that with PIP, making the latter as a better choice as a brightener additive to work with PVA. 
Table 2. Cyclic voltammetric data for zinc deposition in presence of carrier additives.

\begin{tabular}{|c|c|c|c|c|c|}
\hline Electrolyte & $\begin{array}{c}\text { Additive conc. } \\
\mathrm{g} / \mathrm{L}\end{array}$ & $\mathrm{E}_{\mathrm{cp} 2}$ & $\mathrm{I}_{\mathrm{cp} 1}$ & $\begin{array}{c}\mathrm{I}_{\mathrm{cp} 2} \\
\text { Total }\end{array}$ & $\begin{array}{c}\mathrm{I}_{\mathrm{cp} 2} \\
\left(\mathrm{I}_{\mathrm{cp} 2}-\mathrm{I}_{\mathrm{cp} 1}\right)\end{array}$ \\
\hline Plain zinc bath & - & 1.501 & 3.64 & 24.45 & 20.81 \\
\hline Zinc bath + RS & 5 & 1.55 & 3.64 & 31 & 27.36 \\
& 10 & 1.55 & 4.5 & 31.5 & 27.5 \\
\hline Zinc bath + NA & 5 & 1.55 & 3.5 & 27.0 & 23.5 \\
& 10 & 1.55 & 2.0 & 25.0 & 23.0 \\
\hline Zinc bath +TEA & $5 \mathrm{~mL} / \mathrm{L}$ & 1.55 & 3.5 & 24.5 & 21.0 \\
& $10 \mathrm{~mL} / \mathrm{L}$ & 1.58 & 2.5 & 24.0 & 21.5 \\
\hline Zinc bath +TEPA & $5 \mathrm{~mL} / \mathrm{L}$ & 1.55 & 2.50 & 21.1 & 18.6 \\
& $10 \mathrm{~mL} / \mathrm{L}$ & 1.55 & 1.50 & 14.4 & 13 \\
\hline Zinc bath +PVA & 1.5 & 1.55 & 4.0 & 14 & 10 \\
& 2.0 & 1.55 & 3.0 & 13 & 10 \\
\hline Zinc bath + VA & 0.5 & 1.58 & 4 & 33 & 29 \\
& 1.0 & 1.55 & 4 & 27.5 & 23.5 \\
\hline
\end{tabular}

Table 3. Cyclic voltammetric data for zinc deposition in presence of carrier additive and brightener additives.

\begin{tabular}{|c|c|c|c|c|c|}
\hline Electrolyte & $\begin{array}{c}\text { Additive conc. } \\
\mathrm{g} / \mathrm{L}\end{array}$ & $\mathrm{E}_{\mathrm{cp} 2}$ & $\mathrm{I}_{\mathrm{cp} 1}$ & $\begin{array}{c}\mathrm{I}_{\mathrm{cp} 2} \\
\text { Total }\end{array}$ & $\begin{array}{c}\mathrm{I}_{\mathrm{cp} 2} \\
\left(\mathrm{I}_{\mathrm{cp} 2}-\mathrm{I}_{\mathrm{cp} 1}\right)\end{array}$ \\
\hline Zinc bath + PVA & 1.5 & 1.55 & 4.0 & 14 & 10 \\
\hline \multirow{2}{*}{ Bath + PVA + PIP } & 1.0 & 1.55 & 2.5 & 9.0 & 6.5 \\
& 1.5 & 1.56 & 2.0 & 8.0 & 6.0 \\
\hline \multirow{2}{*}{ Bath + PVA + VER } & 0.4 & 1.55 & 2.5 & 8.0 & 5.5 \\
& 0.6 & 1.55 & 2.0 & 7.0 & 5.0 \\
\hline \multirow{2}{*}{ Bath + PVA + ANI } & 0.4 & 1.70 & 2.5 & 7.0 & 4.5 \\
& 0.6 & 1.70 & 2.0 & 5.0 & 3.0 \\
\hline \multirow{2}{*}{ Bath + PVA + VA } & 1.0 & 1.55 & 3.0 & 18.0 & 15.0 \\
& 1.5 & 1.55 & 2.5 & 20.0 & 17.5 \\
\hline \multirow{2}{*}{ Bath + PVA + BZ } & 10.0 & 1.56 & 2.5 & 22.0 & 19.5 \\
& 15.0 & 1.55 & 2.0 & 14.5 & 12.5 \\
\hline
\end{tabular}

\section{Conclusion}

The polarization behaviors, the extent of complexation, peak potential and peak currents and potential cross over etc. observed in the cyclic voltammograms of zinc deposition from an alkaline non-cyanide bath in presence of various carrier and brightener additives help understanding the effect of additives in the zincate bath.

\section{Acknowledgement}

The first author expresses her sincere thanks to the Director, CECRI for the support and permission to publish this paper and Dr. Malathy Pushpavanam expresses her sincere thanks to the All India Council for Technical Education for funding her work at Alagappa Chettiar College of Engineering \& Technology, Karaikudi.

\section{References}

1. H. Geduld, Zinc Plating, ASM International Metals Park, Ohio, 1988 
2. M. Schlesinger and M. Paunovic, Modern Electroplating, $4^{\text {th }}$ Edn, John Wiley \& Sons, New York 2000.

3. S. Shanmugasigamani, M. Pushpavanam, J. Appl. Electrochem. 36 (2006) 315.

4. L. Oniciu, L. Muresan, J. Appl. Electrochem. 21 (1991) 565.

5. J.W. Dini, "Electrodeposition - The Materials Science of Coatings and Substrates", Noyes Publications, New York, 1993.

6. G.A. Hope, G.M. Brown, D.P. Schweinsberg, K. Shimizu, K. Kobayashi, J. Appl. Electrochem. 25 (1995) 890.

7. V.N. Titova, A.A. Javich, N.V. Petrova, V.A. Kazakov, S. Biallozor, B. Electrochem. 16 (1995) 425.

8. J.H.O.J. Wijenberg, J.T. Stevels, J.H.W. de Wit, Electrochim. Acta 43 (1995) 649.

9. J. McBreeb Abd and E.J. Cairns, Adv. Electrochem. Eng. 11 (1978) 273.

10. H.J. Bard, Encyclopedia of Electrochemistry of the Elements, Vol. 5, Marcel Decker Inc, New York, 1982

11. T.S. Lee, J. Electrochem. Soc. 18 (1971) 1278.

12. J. Lee, J.W. Kim, M.K. Lee, H.J. Shin, H.T. Kim, S.M. Park, J. Electrochem. Soc. 151 (2004) C25.

13. J.L. Ortiz-Aparicio, Y. Measa, G. Trejo, R. Ortega, T.W. Chapman, E. Chainet, P. Ozil, Electrochem. Acta 52 (2007) 4742.

14. G.D. Wilcox, P.J. Mitchell, Trans. Inst. Met. Finish 65 (1987) 76.

15. S. Taguchi, A. Aramata, J. Electroanal. Chem. 396 (1995) 131.

16. P.F. Mendez, J.R. Lopez, Y. Meas, R. Ortega, L. Salgado, G. Trejo, Electrochim. Acta 50 (2005) 2815.

17. G. Roventi, T. Bellezze, R. Fratesi, Electrochim. Acta 51 (2006) 2691.

18. A. Ramachandran, S.M. Mayanna, Met. Finish 90 (1992) 61.

19. H.G. Crentz, US Pat 3,853,718, 1974.

20. V. Ravindran, RM. Krishnan, V.S. Muralidharan, Met. Finish 96 (1998) 10.

21. M. Monev, L. Mirkova, I. Krastev, Hr. Tsvetkova, S.T. Rashkov, W. Rightering, J. Appl. Electrochem. 28 (1998) 1107.

22. L. Mirkova, M. Monev, I. Krastev, S. Rashkov, Trans. Inst. Met. Finish 73 (1995) 107.

23. A. Gomes, M.I. de Silva Pereira, Electrochim. Acta 52 (2006) 863.

24. M. Mouanga et al., Surf. Coat. Technol. 201 (2007) 7143.

25. T.C. Hsieh, C.C. Hu, T.C. Lee, Surf. Coat. Technol. 203 (2009) 3111.

26. X. Xiao, X. Yi, P. Zhong, Y. Ou, Corr. Sci. Prot. Technol. 20 (2008) 62.

27. H.B. Muralidhara, Y.A. Naik, H.P. Sachin, G. Achary, T.V. Venkatesha, Ind. J. Chem. Technol. 15 (2008) 259. 